\title{
Modelling interactions of fish, fishers and consumers: should bycatch be taken into account?
}

\author{
Benjamin Blanz $\mathbb{D}$
}

Received: 28 February 2017/Revised: 12 October 2018/Accepted: 12 October 2018/Published online: 27 October 2018

(C) The Author(s) 2018

\begin{abstract}
Consumers' preferences coupled with available fishing technology determine fisheries' harvests and impacts on the ecosystem. In this paper, I investigate the effects of unintended catch, or bycatch, on consumption decisions and harvests. To this end, a multi-species coupled ecosystem economy model including consumer preferences is extended to also include bycatch in harvesting. The resulting equilibria and dynamics of the model are solved analytically. This allows demonstration of the effects of bycatch not only on the ecosystem, which are comparatively well researched, but also on the economic actors harvesting and consuming fish stocks. The main results, besides replicating the finding that bycatch can increase harvesting mortality, are that even strong bycatch may have no effects on stocks and that the harvesting economy may change dramatically depending on bycatch intensity. Therefore, bycatch should indeed
\end{abstract}

Guest editors: Steven J. Degraer, Vera Van Lancker,

Silvana N.R. Birchenough, Henning Reiss \&

Vanessa Stelzenmüller / Interdisciplinary research

in support of marine management

Electronic supplementary material The online version of this article (doi:https://doi.org/10.1007/s10750-018-3799-1) contains supplementary material, which is available to authorized users.

B. Blanz ( $\square)$

Universität Hamburg, Grindelberg 5, 20144 Hamburg,

Germany

e-mail: benjamin.blanz@uni-hamburg.de be taken into account in the economic modelling of fisheries. Furthermore, understanding the interrelation of bycatch and market forces is essential in designing overarching policy where economic effects, such as changing employment, need to be considered while also ensuring sustainable use of the ecosystem.

Keywords Fishery economics · Modelling · Dynamics $\cdot$ Equilibria $\cdot$ Bio-economic systems

\section{Introduction}

The behaviour of human actors is one of the key challenges in sustainable management of ecosystems and especially fisheries management. One of the goals of environmental economics is to develop a better understanding of the interrelation of human behaviour and ecosystem dynamics. With regard to fisheries, this concerns not only the behaviour of fishers, the suppliers on the markets for fish products, but also consumers, the demand side on these markets. These issues are further complicated by imperfect selectivity in harvesting in the fishing process. This unintended catch of other species besides the target species is called bycatch in the following. To better understand the direct and indirect effects that bycatch has on harvesting rates, economic variables and long run stock levels, a model is developed which includes 
bycatch in harvesting in addition to interaction between species within the ecosystem and consumer demand.

Imperfect selectivity is investigated in e.g. Nieminen et al. (2012) and Skonhoft et al. (2012). While the catch of fish which are too young or otherwise too small to be economically attractive are also often considered as bycatch (Davies et al., 2009), these are not included in the following analysis, focussing instead only on the marketable catch. The choice of the fishing vessel, gear and the choice of the fishing area can influence the species composition of the catch but perfect selectivity is seldom possible in practice. Additionally, achieving higher selectivity is generally assumed to be costly (Abbott \& Wilen, 2009; Singh \& Weninger, 2009). However, the fisher may not always be aiming to minimize the catch of other species as these may also have market value. This is especially the case for multi-species fishery, where the simultaneous catch of multiple species is the goal and not something to be avoided. In the model presented in this paper, all catch, targeted and bycatch, is landed and sold on the market. This is enforced by the goods market clearing condition, i.e. there is no waste, everything that is produced has to be consumed.

The effect that bycatch has on the ecosystem is difficult to estimate. This is due to the unreliability of self reported data by fishers and the stochastic nature of bycatch. A number of studies have been performed in order to estimate bycatch amounts (Hall et al., 2000; Lewison et al., 2004; Harrington et al., 2005; Davies et al., 2009). Davies et al. (2009) estimate that on a global scale $40 \%$ of total fishing mortality is due to bycatch, while stating that the true value is likely to be even larger. The mortality of the fish caught as bycatch depends on a number of factors, such as air exposure and temperature changes (Davis, 2002). In any case, it is not small enough to be safely ignored.

A problem that arises in conjunction with bycatch is that fishers may have incentives to discard part of their catch at sea. This may either be in order to avoid exhausting quotas or other management measures enforced at port or to continue fishing, increasing the average value of the fish in the hold. While the implications of discarding by fishers have been studied and shown to be important (e.g. Boyce, 1996; Herrera, 2005), such behaviour is omitted in the model used for this paper in order to keep the analysis tractable. However, the model results are discussed with the possibility of discarding in mind. One measure to reduce the amount of bycatch and hence the overharvesting of non-target species is to ban discarding of bycatch harvests, and sufficiently monitoring compliance. Thereby all fishing mortality becomes subject to existing management measures. One example of such a measure being implemented is the recent ban on discards by the European Union (Borges, 2015). In effect, the model used in this paper is formulated with the implicit assumption that such a ban on discards is in effect and perfect compliance has been achieved. Hence, the model results show the full economic effects of the additional harvests through bycatch.

The behaviour of fishers and the incentives governing them have been investigated by a number of authors (e.g. Boyce, 1996; Singh \& Weninger, 2009), demonstrating that it is important to take the harvesting process into account when designing policy measures, if they are to be incentive compatible. Management approaches discussed in the literature include transferable or vessel specific quotas, landing taxes, gear specific taxes and licensing fees. The effect of transferable quotas is investigated in Boyce (1996), where outcomes under management with transferable quotas are compared to the case without any management, for a single period of harvesting. It is found that the optimal solution can only be achieved if both the target and bycatch species are managed using quotas. In a similar setting, Abbott \& Wilen (2009) investigate the individual incentives of fishermen using a game theoretic approach, finding that the policy decision maker is quite restricted in their decision making if large amounts of discards are to be avoided. Herrera (2005) makes the point that in a quata system, bycatch should not be interpreted as a production externality but rather as a stochastic risk that the fishermen need to take into account. Furthermore, discarding of bycatch by fishermen is expensive to observe for the decision maker, leading to information asymmetry and moral hazards. Herrera analyses the effect of taxes, trip limits and value-based quotas, and finds that taxes welfare dominate both other types of management. The effect of transferable quotas versus fixed quotas is investigated by Holland (2010) with a focus on rare stochastic bycatch events. In this context, purchasing additional bycatch quota can be seen as a form of insurance, allowing the fisher to continue operating after a bycatch event occurs. Holland explores the effects that quota markets have on fishers' profits as 
well as risks compared to fixed quota allocation. Furthermore, he explores how the risks can be reduced with market insurance and pooling approaches, which are reported to be quite common even though they are not always formally agreed upon.

However, the incentives that fishers face are not entirely controlled by policy considerations, but strongly dependent on the prices for fish products on the goods markets. Therefore, if the behaviour of fishers is to be modelled, these markets should also be included. A key result of previous research that includes the consumers is the identification of the significant effect that consumer preferences have on the dynamics and equilibria of the ecosystem (Baumgärtner et al., 2011). The consumer preferences for diversity in consumption of fish, in particular, may cause sequential collapse of ecologically independent species (Quaas \& Requate, 2013). This would be unexpected for an observer not aware of the economic actors. These results are a strong argument for ecosystem-based management approaches (Möllmann et al., 2014) and for taking human behaviour into account.

To investigate the combined effects of bycatch, fisher behaviour and consumer preferences on fish stocks, it is necessary to include bycatch as well as consumer preferences in the model. The coupled ecosystem economy models used in Baumgärtner et al. (2011) and Quaas \& Requate (2013) but also in others (e.g. Derissen et al., 2011; Quaas et al., 2013) include consumer preferences, fishers and ecosystem stocks, but fisheries are simplified in such a way that each target species can be harvested perfectly independently of the other species present. These models have been used successfully to investigate how consumer preferences can cause over-fishing of the targeted species, but not to investigate the effects of bycatch. Hence, in this work, the coupled bioeconomic model developed by Quaas \& Requate (2013) is extended to include bycatch in harvesting in order to investigate the combined effects of bycatch and human behaviour. This model consists of a multispecies stock-based ecosystem module and an economy model in which consumers and harvesting firms determine harvests by maximizing their utility and profits, respectively, which in turn depend on the current state of the ecosystem.

To answer the question posed in the title, if bycatch should be considered in economic modelling of fisheries, conditions are determined under which the model results are independent of the amount of bycatch. Furthermore, it is shown that bycatch can significantly increase the fishing mortality, increasing the risk of catastrophic over-fishing, but also may have dramatic effects on the harvesting firms.

The remainder of this paper is structured as follows: First a detailed explanation of the new model, extended from Quaas \& Requate (2013) to include bycatch, is given. Following the model description, results are shown for different bycatch intensities, in addition to targeted catch, and keeping the total catch per firm constant. In the final section, these results are discussed, followed by concluding remarks as to the importance of the results for fisheries management.

\section{Model design}

In order to investigate the consequences of interactions in harvesting between species caused by bycatch, these need to be disentangled from interactions between species stemming from ecological properties of the species, or preferences for certain proportions of species in consumption. Only if all of these avenues of interaction between species are included in the model can the direct effects of bycatch be distinguished from those caused by indirect effects from market adjustments. With this aim, an existing model from the literature (Quaas \& Requate, 2013) which includes interaction between the demand for different species was extended to also include technological interaction in harvesting and ecosystem interaction between species. With these extensions, the model was then fully solved, determining the full equations of motion for the coupled system.

In order to accommodate empirical evidence on the limited willingness of consumers to substitute one species for another in consumption (Barten \& Bettendorf, 1989; Asche et al., 1997; Fousekis \& Revell, 2004), the Dixit-Stiglitz utility function (Dixit \& Stiglitz, 1977) is chosen by Quaas \& Requate (2013). The parameter $\sigma$ in that function can be interpreted as the preferences for a diversity in the consumption of fish. The addition of bycatch does not change the utility function, but it does create a further restriction on the household optimisation problem in addition to the (unchanged) budget constraint. In contrast to the case without bycatch, the ratio in which species are 
supplied is not necessarily free, but may be restricted by the properties of the harvesting gear. The firm optimisation problem is changed to properly reflect the extra harvests achieved with each gear. The number of firms employing a specific combination of vessel type and gear, a certain métier, depends on the prices and quantities of all species that are caught using that vessel and gear combination. Therefore, market prices are not only related through the demand function, but also through the available harvesting technology. The ecosystem portion of the model is based on Baumgärtner et al. (2011). The fish stocks are represented by a standard multi-species biomass growth model. While ecological interactions between species can be included in the model, the parametrisation used in this paper excludes them.

\section{Ecosystem properties}

The ecosystem contains $\bar{i}$ species, which are modelled using stock variables to measure the current amount of biomass of each species relative to the ecosystem's carrying capacity for each species. Stocks are denoted by $x$ with indexes for species $i \in I$, where $I$ is the set of all species $I=[1, \bar{i}] \cap \mathbb{Z}$. Species are assumed to grow each period due to intrinsic growth $g_{i t}$ and are diminished by harvests $H_{i t}$. This change in stocks is modelled by differential equations, determining the dynamics of the model.

$\dot{x}_{i t}=g_{i t}\left(\mathbf{x}_{t}\right)-H_{i t}$

The vector of ecosystem stocks $\mathbf{x}$ completely determines the state of the model. The other variables are modelled as adjusting instantaneously to changed stocks in each period. Their adjustment processes are not resolved within the model. In the following, all variables without a time index, are taken to be contemporary.

Intrinsic growth is represented by the logistic growth function $g_{i}(\mathbf{x})$, which depends on the entire vector of stocks, due to possible interactions between species, which are measured by the species-specific interaction vectors $\gamma_{i}$. It is possible for intrinsic growth to become negative, if stocks fall below minimum viable population levels

$$
g_{i}(\mathbf{x})=r_{i}\left(x_{i}-\underline{x}_{i}\right)\left(1-\frac{\gamma_{i} \mathbf{x}}{\kappa_{i}}\right) \text {. }
$$

Harvesting properties

Per period harvests of each species are the result of choices made by the economic actors within the model. As such harvesting pressure is not an exogenously set parameter, but is endogenously determined depending on the state of the ecosystem, available harvesting gear and vessel types and consumer preferences.

The component of the model describing the harvests includes $\bar{k}$ métiers. In the context of this model, a métier encompasses all that is necessary for the fisher to harvest which is not dependent on the effort i.e. all upfront investments that are necessary to start operating. This includes fishing gear, vessel, license costs and similar expenditures. Each firm is assumed to employ a single vessel with a single gear type. While individual firms may not change their métier, the economy wide fleet size for each métier is dynamic. The change of gear in use occurs through market entry and exit of firms performing different métiers. Métiers are indexed by $k \in K$, where $K$ is the set of all métiers $K=[1, \bar{k}] \cap \mathbb{Z}$. Each has a certain target species, but may also catch other species present, as bycatch.

In the case without bycatch, it is assumed that the market supports at most one métier per targeted species.

\section{Assumption $1 \quad \bar{k}=\bar{i}$}

To arrive at this assumption it can be imagined that initially there are more métiers practised. However, for each species, one gear and vessel combination will be the most efficient at harvesting that species. Implying that firms practising these most efficient métiers will be able to sell at lower prices, compared to those practising less efficient métiers, driving them out of the market. As the different species are imperfect substitutes in consumption, one métier per species will be left.

Total harvest $H_{i}$ of species $i$ is calculated as the number of firms practising métier $k\left(n_{k}\right)$ multiplied by the per firm harvest of species $i$ practising métier $k$ $\left(h_{i k}\right)$ summed over all métiers. 


$$
H_{i}=\sum_{k=1}^{\bar{k}} n_{k} h_{i k}\left(e_{k}, x_{i}\right)
$$

The per firm harvest is described by a generalized Gordon-Schaefer production function (Clark, 1990). It is a function of the effort employed by firms practising the métier $e_{k}$ and the stock being harvested $x_{i}$. Harvesting effort $e_{k}$ experiences diminishing returns, governed by the returns to effort $\epsilon$. However, harvest is not only determined per species as in Quaas $\&$ Requate (2013), but also per métier. The fisher may choose the métier $k$, but she has no direct control of species of fish she catches. Hence, the total amount harvested of a specific species $i\left(H_{i}\right)$ depends on the effort $e_{k}$ made practising all métiers $k$ capable of catching that species $\left(k \in\left\{K \mid v_{i k}>0\right\}\right)$. The gear effect is governed by the gear matrix $v$. The elements of which $\left(v_{i k}\right)$ specify the catchability for each of species $i$ by métier $k$.

$$
h_{i k}\left(e_{k}, x_{i}\right)=v_{i k} e_{k}^{\epsilon} \chi\left(x_{i}\right)
$$

The métiers and species are indexed in such a way that the $l$ th métier has the $l$ th species as its target. It is assumed that each métier is the most efficient for its target. This implies that in the $l$ th row $v$ written as $v_{i=l}$ the largest element will be at the $l$ th position.

Assumption $2 \quad \arg \max _{k} v_{i=l}=l: k \in K$

In the case of perfectly targeted harvesting, i.e. no bycatch, $v$ is a diagonal matrix and Assumption 2 is trivially satisfied. The diagonal elements of $v$ specify the métier efficiency for the harvest of each species. Each species is harvested by a single métier and activity in that métier does not yield harvests for other species. More formally $h_{i k}>0$ for $k=i$ and $h_{i k}=0$ otherwise. Conversely, in the case with bycatch, modelled in this paper, any métier may catch any species i.e. $h_{i k} \geq 0 \forall k \in K, i \in I$ subject to Assumption 2. In both cases, it is assumed that no useless métiers exist. A useless métier would be less efficient than an existing one at harvesting the same species in the same ratio or would yield no harvest at all given the current stock levels. This implies that the product of the stock-dependent harvesting efficiency, described below, and the gear efficiency matrix has full rank.

Assumption $3 \operatorname{rank}(\chi v)=\bar{k}$
Species abundance influences the harvest returns per effort through the harvestability function $\chi_{i}\left(x_{i}\right)$. The harvestability function captures changes in harvest yield due to changing stocks. A less abundant species is more difficult to catch compared to one with high stock levels.

$\chi_{i}\left(x_{i}\right)=x_{i}^{\chi_{i}}$

In the following $\chi_{i}\left(x_{i}\right)$ will be abbreviated as $\chi_{i}$. A further shorthand $\chi$ (no index) is used in some of the derivations in the appendix and in Assumption 3. It specifies a square matrix containing the $\chi_{i}$ along the diagonal and zeros off the diagonal.

The effort of each firm is determined under the assumption of perfect markets for harvested goods and labour. Each firm takes stock levels $x_{i}$, prices $p_{i}$ and wages $\omega$ as fixed and maximizes individual short-term profits. Fixed costs associated with harvesting $\phi_{k}$ are determined by the métier practised. The representative firm per métier then solves the following profitmaximizing problem in order to determine their effort level $e_{k}$.

$$
\max _{e_{k}} \sum_{i=1}^{\bar{i}} h_{i k}\left(e_{k}, x_{i}\right) p_{i}-\omega e_{k}-\phi_{k}
$$

Due to the assumed perfect markets, firms' profits will be zero. This in conjunction with profit maximization results in the zero-profit optimal métier-specific effort level $e_{k}^{*}$, the derivation of which can be found in Appendix A.

$e_{k}^{*}=\frac{\phi_{k}}{\omega} \frac{\epsilon}{1-\epsilon}$

The optimal effort level differs for individual métiers as each métier is assumed to have specific positive fixed costs $\phi_{k}$. Substituting $e_{k}^{*}$ into the harvesting production function (4) yields the per firm métierspecific equilibrium harvest

$$
h_{i k}\left(x_{i}\right)=v_{i k} e_{k}^{* \epsilon} \chi\left(x_{i}\right) \text {. }
$$

\section{Household properties}

Households are modelled by a single representative household. The household's preferences over consumption of fish $Q$ and a numeraire commodity $y$ are formalized in the household utility function. 


$$
U(Q, y)= \begin{cases}y+\alpha \frac{\eta}{\eta-1} Q^{\frac{\eta-1}{\eta}} & \text { for } \eta \neq 1 \\ y+\alpha \ln Q & \text { for } \eta=1\end{cases}
$$

The parameter $\eta>0$ describes the constant demand elasticity of fish, while $\alpha \geq 0$ measures the relative importance of fish consumption in overall consumption. The household's preferences over the available species of fish are modelled using a Dixit-Stiglitz utility function (Dixit \& Stiglitz, 1977).

$$
Q=Q(\mathbf{q})=\left(\sum_{i=1}^{\bar{i}} q_{i}^{\frac{\sigma-1}{\sigma}}\right)^{\frac{\sigma}{\sigma-1}}
$$

The elasticity of substituting between consumption levels of different species $q_{i}$ is measured by $\sigma>0$. Perfect substitution would be achieved for $\sigma \rightarrow \infty$, while lower values indicate limited substitutability of fish species in consumption.

The representative household maximizes (9), choosing $y$ and the $q_{i}$ subject to the household budget constraint:

$$
\omega=y+\sum_{i=1}^{\bar{i}} p_{i} q_{i}
$$

In each period, the household receives income from providing labour to the fisheries and manufacturing sectors. All household income $\omega$ is spent either on fish, according to the amounts consumed $q_{i}$ and prices $p_{i}$, or on a manufactured good $y$ the price of which has been normalised to one. To keep the analysis tractable, no saving or other capital accumulation is possible in the model. The manufactured good is taken to represent all other consumption, besides fish. The wage rate $\omega$ is determined by the marginal productivity of labour. This is defined by the production function of the numeraire commodity, which is shown in the following section.

As species are not supplied independently, due to the introduction of bycatch in harvesting, the goods market clearing condition implies an additional restriction on household demand, not present in Quaas \& Requate (2013).
$q_{i}=H_{i}=\sum_{k=1}^{\bar{k}} n_{k} h_{i k}\left(x_{i}\right)$

Furthermore, basic realism forbids contemplating negative firms. This is formalized by the non-negativity conditions on each of the $\bar{k}$ numbers of firms variables $n_{k}$.

$n_{k} \geq 0$

As it is not known ex ante if this condition will be binding or not, it cannot be simplified to an equality.

In order to solve the household optimisation problem under these conditions, the Kuhn-Tucker conditions are used (Kuhn, 2014). To simplify the analysis, the goods market clearing condition (12) is substituted into the sub-utility for fish (10) and the budget restriction is reformulated.

$$
\begin{aligned}
\tilde{Q} & =\tilde{Q}(\mathbf{n})=\left(\sum_{i=1}^{\bar{i}}(\underbrace{\sum_{k=1}^{\bar{k}} n_{k} h_{i k}\left(x_{i}\right)}_{q_{i}})^{\frac{\sigma-1}{\sigma}}\right)^{\frac{\sigma}{\sigma-1}} \\
c_{k} & =e_{k}^{*} \omega+\phi_{k} \\
& =\phi_{k}\left(1+\frac{\epsilon}{1-\epsilon}\right)
\end{aligned}
$$

Hereby the $c_{k}$ represents the operating costs of each firm of type $k$. The firm costs do not depend on any variables as it is assumed that firms operate at the zeroprofit profit-maximizing level (7). Given that firms operate at this equilibrium level, the sum of costs multiplied with the number of firms must equal the sum of prices multiplied by consumed amounts of species.

$\sum_{k=1}^{\bar{k}} c_{k} n_{k}=\sum_{i=1}^{\bar{i}} p_{i} q_{i}$

This is substituted into (11) to yield the reformulated budget constraint.

$$
y=\omega-\sum_{k=1}^{\bar{k}} c_{k} n_{k}
$$

The representative household now chooses the type and number of bundles of fish in order to maximize 
utility. Bundles consist of certain amounts of each harvestable species. The composition of the bundles is defined by equilibrium output of a single firm of each type $h_{k}(\mathbf{x})$.

$$
h_{k}(\mathbf{x})=\left(\begin{array}{c}
h_{1 k}\left(x_{1}\right) \\
\vdots \\
h_{\overline{i k}}\left(x_{\bar{i}}\right)
\end{array}\right)
$$

The Lagrangian of the household optimisation problem then is

$$
\begin{aligned}
& \mathscr{L}(\mathbf{n})=\omega-\sum_{k=1}^{\bar{k}} c_{k} n_{k} \\
& +\alpha \frac{\eta}{\eta-1}\left(\sum_{i=1}^{\bar{i}}\left(\sum_{k=1}^{\bar{k}} n_{k} h_{i k}\left(x_{i}\right)\right)^{\frac{\sigma-1}{\sigma}}\right)^{\frac{\sigma \eta-1}{\sigma-1 \eta}}-\sum_{k=1}^{\bar{k}} \lambda_{k}\left(-n_{k}\right)
\end{aligned}
$$

As $\ln (Q)$ is the continuous extension of $\frac{\eta}{\eta-1} Q^{\frac{\eta-1}{\eta}}$ the first-order conditions derived using the above equation also extend to the case $\eta=1$. The first-order conditions are

$$
\begin{aligned}
\frac{\mathrm{d} \mathscr{L}(\mathbf{n})}{\mathrm{d} n_{k}} & =0 \\
\lambda_{k} & \geq 0 \\
-n_{k} & \leq 0 \\
-\lambda_{k} n_{k} & =0 .
\end{aligned}
$$

To determine the solution to the household optimisation problem, it is split into cases depending on the number of métiers practised. The cases considered are

1. All métiers are practised

2. Only one métier is practised

3. Not all métiers are practised, but more than one

In order to keep the analysis simple, for the remainder of this paper only two species and métiers are considered. This removes the third case from consideration.

Assumption $4 \quad \bar{k}=\bar{i}=2$

\section{Case 1: All Métiers practised}

For the case where none of the non-negativity conditions are binding, the restriction can simply be omitted and the solution to the household optimisation problem can be found using a basic Lagrangian approach. The derivation of the household demand function for individual species of fish can be found in Appendix B.1. This function relates the amount of each species demanded (and consumed) to the prices of all available species.

$q_{i}=\alpha^{\eta} p_{i}^{-\sigma}\left(\sum_{i^{\prime}=1}^{\bar{i}} p_{i^{\prime}}^{1-\sigma}\right)^{\frac{\sigma-\eta}{1-\sigma}}$

The household demand function in this case is unaffected by the bycatch introduced into harvesting, and is therefore equal to the one found in Quaas \& Requate (2013). The derivation of prices and number of active firms, however, is somewhat more complicated, due to the additional interrelation of prices and number of firms on the supply side.

The number of active firms in this case is found by solving the goods market clearing conditions for each of the $\bar{i}$ species simultaneously. The number of firms per métier is then determined by solving the corresponding linear system of equations.

$\mathbf{n}={ }^{n} A^{-1 n} \mathbf{b}$

The components of the linear system of equations are given by

$$
\begin{aligned}
{ }^{n} A & =v \operatorname{diag}\left(\mathbf{e}^{* \epsilon}\right) \\
{ }^{n} \mathbf{b} & =\chi^{-1}(\mathbf{x}) \mathbf{q}(\mathbf{p}) . \\
{ }^{n} b_{i} & =\chi^{-1}\left(x_{i}\right) q_{i}(\mathbf{p})
\end{aligned}
$$

The derivation of the above can be found in Appendix B.3.

For the case with only two species and métiers, i.e. Assumption 4 holds, the solution to the linear system of equations determining the number of firms practising each métier can be written as follows:

$$
n_{1}(q(\mathbf{p}))=\frac{v_{22} \chi_{2} q_{1}(\mathbf{p})-v_{12} \chi_{1} q_{2}(\mathbf{p})}{e_{1}^{* \epsilon} \chi_{1} \chi_{2}\left(v_{11} v_{22}-v_{12} v_{21}\right)}
$$


$n_{2}(q(\mathbf{p}))=\frac{v_{11} \chi_{1} q_{2}(\mathbf{p})-v_{21} \chi_{2} q_{1}(\mathbf{p})}{e_{2}^{* \epsilon} \chi_{1} \chi_{2}\left(v_{11} v_{22}-v_{12} v_{21}\right)}$

In the case of all métiers being practised, prices will equal average production costs of the harvesting firms. Prices are determined by solving the zero-profit conditions of all $\bar{k}$ métiers simultaneously. This yields prices as the solution of a linear system of equations.

$$
\mathbf{p}={ }^{p} A^{-1 p} \mathbf{b}
$$

The components of which are defined as follows:

$$
\begin{aligned}
{ }^{p} A & =v^{\top} \chi \\
{ }^{p} \mathbf{b} & =\left(\begin{array}{c}
{ }^{p} b_{1} \\
\vdots \\
{ }^{p} b_{\bar{k}}
\end{array}\right) \\
{ }^{p} b_{k} & =\phi_{k}\left(1+\frac{\epsilon}{1-\epsilon}\right)\left(\frac{\phi_{k}}{\omega} \frac{\epsilon}{1-\epsilon}\right)^{-\epsilon}
\end{aligned}
$$

The derivation of the individual components can be found in Appendix B.2. Deriving prices in this way requires Assumption 1.

In the case with only two species and two métiers is considered, i.e. Assumption 4 holds, the solution to the above linear system of equations can be written as follows:

$$
\begin{aligned}
& p_{1}=\left(\chi_{1}\right)^{-1}\left(v_{11} v_{22}-v_{12} v_{21}\right)^{-1}\left(v_{22}^{p} b_{1}-v_{21}^{p} b_{2}\right) \\
& p_{2}=\left(\chi_{2}\right)^{-1}\left(v_{11} v_{22}-v_{12} v_{21}\right)^{-1}\left(v_{11}^{p} b_{2}-v_{12}^{p} b_{1}\right) .
\end{aligned}
$$

\section{Case 2: Only One Métier Practised}

With only one métier practised, the household optimisation problem is simplified from the one with $\bar{k}$ choice variables to only one. This is achieved by using the fact that the number of active firms for all other métiers is zero. The demand for the bundle of harvested goods produced by the single métier is given by Eq. (31), the derivation of which can be found in Appendix A. $n_{k}=c_{k}^{-\eta} \alpha^{\eta}\left(\sum_{i=1}^{\bar{i}} h_{i k}\left(x_{i}\right)^{\frac{\sigma-1}{\sigma}}\right)^{\frac{(\eta-1) \sigma}{\sigma \sigma-1}}$

The demand for individual species follows from the goods market clearing condition (12), where $n_{k}$ is replaced by the above demand function and $h_{i k}\left(x_{i}\right)$ is given by (8).

$$
\begin{aligned}
q_{i} & =n_{k} h_{i k}\left(x_{i}\right) \\
& =\alpha^{\eta} c_{k}^{-\eta} h_{i k}\left(x_{i}\right)\left(\sum_{i=1}^{\bar{i}} h_{i k}\left(x_{i}\right)^{\frac{\sigma-1}{\sigma}}\right)^{\frac{(\eta-1) \sigma}{\sigma-1}}
\end{aligned}
$$

Prices can then be determined using the inverse demand function, which is obtained during the derivation of the demand function for Case 1 in Appendix B.1

$$
p_{i}=\alpha q_{i}^{-\frac{1}{\sigma}} Q^{\frac{\eta-1}{\eta}-\frac{\sigma-1}{\sigma}} \text {. }
$$

\section{Switching between cases}

The conditions for switching between these two cases are derived from the first-order conditions of the household optimisation problem. Per Eq. (23), whenever the number of active firms for a specific métier $k$ becomes zero the corresponding slip parameter $\lambda_{k}$ becomes greater than zero. Given Assumption 4, it can be assumed without further loss of generality that Métier 1 is the one not practised, while Métier 2 is practised. More formally $n_{1}=0$ and hence $\lambda_{1}>0$ while $n_{2}>0$ and $\lambda_{2}=0$. Substituting this into (20) yields the condition for the number of firms practising métier 1 to be zero.

$0>\sum_{i=1}^{\bar{i}}\left(\chi_{i} v_{i 2}\right)^{\frac{\sigma-1}{\sigma}}\left(\frac{v_{i 1}}{v_{i 2}}-1\right)$

The derivation of (34) can be found in Appendix B.5.

Given Assumptions 1, 2 and 3, in a parametrisation without bycatch, all métiers would be practised in order to maximize welfare. This can be seen from (34) as follows: In the case without bycatch the elements of $v$ off the diagonal $\left(v_{i k} i \neq k\right)$ would be zero, causing at least one of the factors in each term of the sum to become zero and hence the entire sum to be zero, this would violate the condition for inactivity of a single métier. If parametrised in such a way, the model 
replicates those described in Quaas et al. (2013) and Quaas \& Requate (2013).

An exception to the above is the extinction of a species. In this case, without bycatch, the métier targeting the extinct species would yield no harvest at all, violating Assumption 3. To continue iteration of the model in this case, it is reparametrised to exclude the extinct species and the useless métier, ensuring that Assumption 3 is satisfied once more. This method is employed after the first extinction event shown in Fig. 1.

Labour market and the numeraire commodity

The representative household supplies an amount of labour normalised to unity. This labour can either be employed in the harvesting sector, as effort $e$, or in the manufacture of the numeraire commodity $y$. The latter is produced with labour as its sole input and constant labour productivity equal to the wage rate $\omega$. As a perfect labour market is assumed, the amount of labour employed in each of the sectors will balance such that the marginal productivity of labour is equal in both.

Given the effort levels determined for the harvesting sector, and the costs associated with the métiers, the production of the numeraire commodity is determined by the labour productivity (equal to the wage rate $\omega$ ) multiplied by the amount of labour available to the manufacturing sector minus economy-wide fixed costs of harvesting, closing the model

$y=\omega\left(1-\sum_{k=1}^{\bar{k}} n_{k} e_{k}^{*}\right)-\sum_{k=1}^{\bar{k}} n_{k} \phi_{k}$.

\section{Parametrisation}

The standard parametrisation of the model used in this section is shown in Table 1. The model includes two species which are harvested, without bycatch, by two métiers. Bycatch is added later in the analysis and the results compared to the standard parametrisation. The first species has a higher intrinsic growth rate and is easier to harvest compared to the second species. The species are not prone to intrinsic stock collapse and do not compete for resources, i.e. the species grow independently of each other. Métier 1 is associated with higher fixed costs compared to Métier 2.
Household preferences allow for some substitution between fish species. A low weight of fish consumption in utility was chosen for the standard parametrisation to ensure that the stocks are not immediately depleted.

Species' intrinsic growth rates are chosen for demonstration purposes but are broadly in line with the motivation. Interspecies competition and minimum population thresholds are parametrised out of the model in order to not confuse results. The carrying capacities of both species have been normalised to one. The ecosystem parametrisation impacts the model results through the relative differences in stock growth. In the chosen parametrisation, the only difference in growth comes from the intrinsic growth rates. As the household would ideally consume equal amounts of each species, the price for the more productive species will be lower.

Positive fixed costs $\phi$ ensure positive harvesting effort in the firm optimisation problem. The wage and hence the price of the numeraire commodity are normalised to unity. The métier-specific harvesting efficiencies are chosen to balance the intrinsic growth rates of the species. In the standard parametrisation, bycatch harvesting efficiencies are set to zero.

The choice of $\eta=1$ and $\sigma=2$ follows Quaas \& Requate (2013). These values ensure limited substitutability between the consumption of fish species i.e. a preference to substitute reduced consumption of one species by another fish species instead of the numeraire commodity. Values of $\sigma>1$ ensure that the marginal utility of species $i$ remains positive even if the consumption of another species becomes zero. Furthermore, $\eta=1$ ensures that if only one métier is practised, the number of firms practising that métier is independent of the bycatch intensity. Thereby the direct effect of bycatch can be observed in results without adjustment in the number of firms.

The coastal fisheries in the German Bight are the real world motivation for the parametrisation. This fishery mainly targets two species, plaice and sole, where one species, plaice, is typically larger than the other, sole. This implies that plaice can be caught with near perfect selectivity as a mesh size aimed at catching plaice will allow sole to pass through. The same cannot be said when targeting sole. In that case, a smaller mesh size is necessary, catching both species. This bycatch structure implies that the top right entry of the gear matrix $v_{12}$ (the catch of Species 1 by Métier 

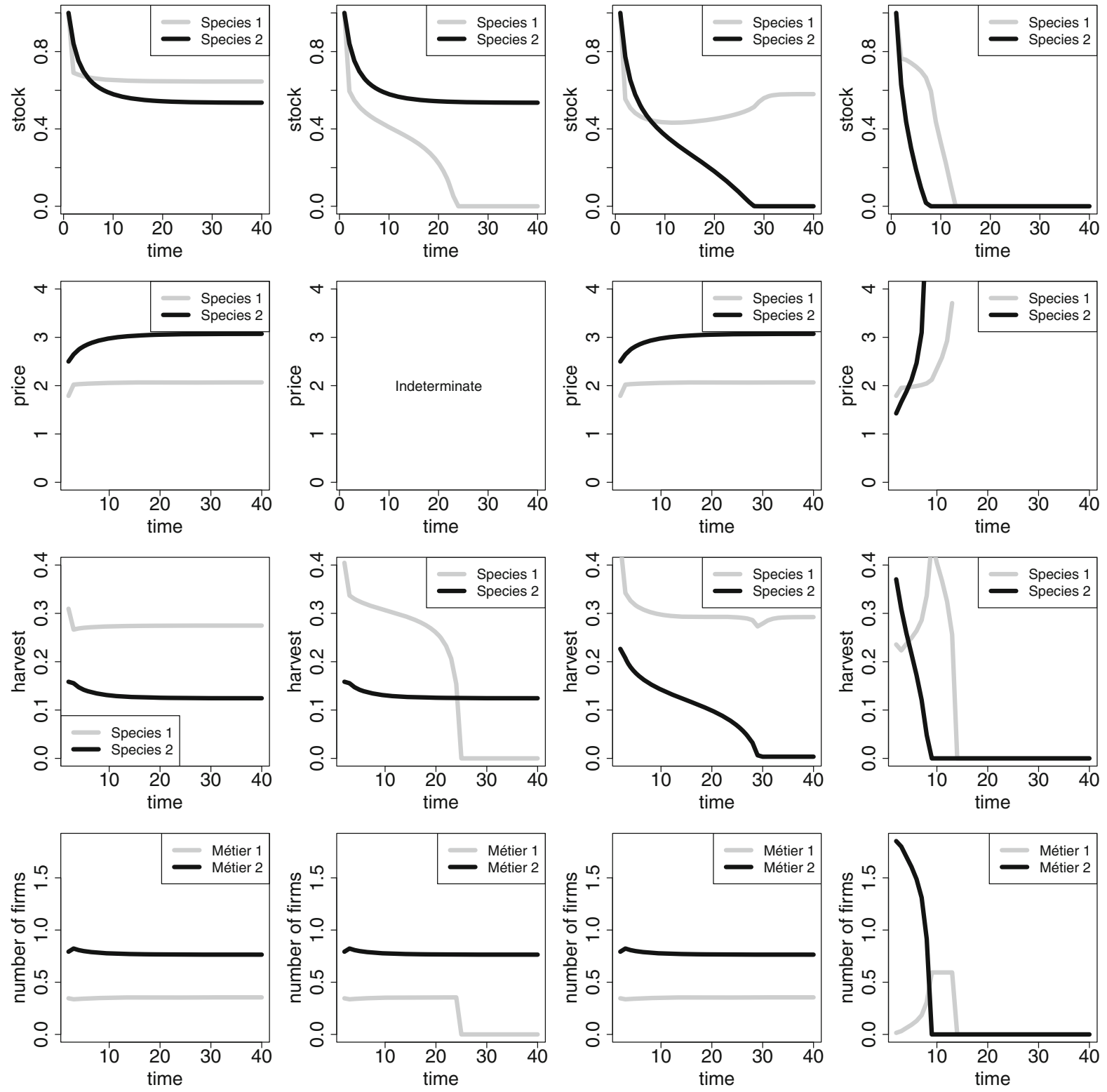

Fig. 1 Simulation results without (left column) and with bycatch $\left(v_{12}=0.24\right.$ other columns $)$ with different economic adjustment behaviours enabled. Left column: full model interactions, no bycatch. Centre left column: number of firms fixed to no bycatch levels, no endogenous behaviour by economic actors. Prices can not be determined for this setting, as markets are not allowed to function. Centre right column:
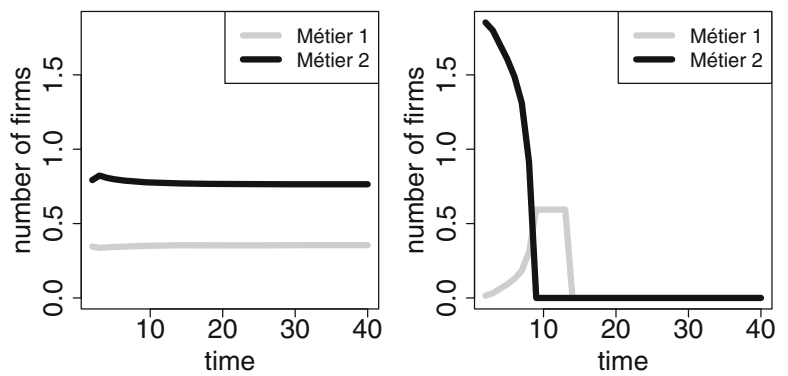

number of firms and prices fixed to no bycatch levels, endogenous effort choice by harvesters. Right column: full model interactions. For all columns, the importance of fish consumption in household utility has been increased to make the results more visible $(\alpha=0.8)$. All other parameters as in Table 1

\section{Condition for no effect of bycatch}

2) is positive. The
following sections.

An interesting analytical result can be derived from the model equations. As prices are directly linked with harvests and hence stocks, if prices do not change in 
Table 1 Standard parameter values used in this paper

\begin{tabular}{|c|c|c|}
\hline Symbol & Description & Value \\
\hline \multicolumn{3}{|c|}{ Ecosystem parameters } \\
\hline $\bar{i}$ & Number of species & 2 \\
\hline $\bar{k}$ & Number of harvesting métiers & 2 \\
\hline$r$ & Species-specific intrinsic growth rates & $(1.2,0.5)^{\top}$ \\
\hline$\kappa$ & Species-specific carrying capacity & $(1,1)^{\top}$ \\
\hline$\underline{x}$ & Species-specific minimum viable population & $(0,0)^{\top}$ \\
\hline$\gamma$ & Interspecies resource competition matrix & $(10)$ \\
\hline \multicolumn{3}{|c|}{ Harvesting firms parameters } \\
\hline$\omega$ & Wage rate & 1 \\
\hline$\epsilon$ & Returns to effort & 0.5 \\
\hline$v$ & Métier- and species-specific harvesting efficiency & $\left(\begin{array}{l}10 \\
00.4\end{array}\right)$ \\
\hline$\chi$ & Species-specific stock dependent harvesting efficiency & $(0.33,0.33)^{\top}$ \\
\hline$\phi$ & Métier-specific fixed costs & $(0.8,0.25)^{\top}$ \\
\hline \multicolumn{3}{|c|}{ Household parameters } \\
\hline$\alpha$ & Importance of fish consumption in household utility & 0.4 \\
\hline$\eta$ & Substitution elasticity of fish consumption & 1 \\
\hline$\sigma$ & Substitution elasticity between fish species & 2 \\
\hline
\end{tabular}

This parametrisation does not include bycatch as the elements of $v$ off the diagonal are zero. Assumptions 1, 2, 3 and 4 are all satisfied by this parametrisation programming language (R Core Team, 2017). Steady states are then determined using the $\mathrm{R}$ package rootSolve (Soetaert \& Herman, 2009, Chap. 7). To determine the effect that additional bycatch has on the model results, the interior equilibria of the model are investigated. This equilibrium is stable with both stocks present. The model contains a number of other stable equilibria, most notably the asymmetric stable equilibria, where one species survives while the other is extinct, and of course total extinction.

\section{Results}

To fully determine the effect that bycatch has not only on ecosystem stocks, but also on economic variables, the model introduced above incorporates economic activities as well as ecosystem properties in a fully coupled manner. Thereby model results show the indirect effects of bycatch in addition to the direct changes in harvesting efficiency. These indirect effects are the results of the fisheries market adjusting to changes in harvesting costs, resulting from changed harvesting efficiencies (the direct effects). These adjustment processes are revealed in the responses of 
prices and number of firms practising specific métiers to changing harvesting efficiencies. The economic adjustment processes are assumed to be instantaneous compared to the more slowly adjusting ecosystem stocks. Hence the short- and long-term results of different levels of bycatch may differ significantly until a global equilibrium, also known as a steady state, of the model is reached.

The key result derived from the model is that the total effect of bycatch may strongly differ from the direct effect. This is especially the case when more than one period is considered, as the adjustment processes causing the indirect effects not only depend on parameters but also on (changing) stock levels. Hence, the deviation between predictions may compound over time. An example of how the indirect effects alter outcomes and the difference between estimates of the impact of bycatch is shown in Fig. 1 for ecosystem stocks and selected economic variables. For these model runs, consumer demand for fish was increased to better illustrate the result $(\alpha=0.8)$. The leftmost column shows how the ecosystem stocks and economic variables adjust in response to each other under the assumption of perfect selectivity. The only interactions between the harvests of the two species in this case stem from consumer preferences. For the centre left column, bycatch is added to Métier 2 $\left(v_{12}=0.24\right)$, while the number of harvesters practising each métier is fixed to the levels derived without bycatch. This shows the direct results of bycatch on stocks over time, omitting any economic adjustment. Prices cannot be determined in this context, as markets are not allowed to adjust such that demand and supply equal. As is to be expected, the increased harvesting efficiency for Species 1 causes its stocks to decline, while harvests of the other species, not impacted by bycatch, remain constant. For the centre right column, some economic behaviour is enabled. There, harvesters' effort level is endogenously determined, maximizing profits given the fixed prices taken from the no bycatch case. Even this limited economic behaviour significantly changes results compared to the previous simulations. Finally, in the rightmost column, economic variables are fully endogenous. The market for harvested products adjusts to the higher overall harvesting efficiency of Métier 2. The immediate response is that a significantly larger number of firms choose to practice this now more attractive métier compared to the no bycatch scenario.
As the total amount of labour available to the fishing sector is limited, this causes a corresponding drop in the number of firms practising the other métier. This simultaneous drop in the use of Métier 1 causes a drop in harvests of Species 1. This overcompensates the added harvesting of Species 1 from bycatch in the use of Métier 2. As a result total harvests of Species 1 are lower than in the no bycatch case on the far left, even though overall harvesting efficiency has increased. The continuing adjustments over time are a response to changing ecosystem stocks. Changed stocks impact the market as they make up part of the harvesting costs. This can be observed in the strongly increasing prices, as stocks are depleted. However, the increase in prices is not sufficient to deter consumers, leading to the complete depletion of both species in this scenario. This extreme outcome is partly caused by the high relative importance of fish consumption in utility for these illustrations $(\alpha=0.8)$. For lower values of that parameters, the increase in prices is sufficient for consumers to reduce consumption, reducing harvests. In those cases, interior equilibria exist.

A second result relates to the interior equilibria or steady states of the model, depending on various bycatch intensities. In this context, decreases in the target harvesting efficiency with increasing bycatch are also considered. The stable interior equilibria for varying levels of the bycatch harvesting efficiency of Métier 2, i.e. the efficiency of catching Species 1 by Métier 2 are shown in the left column of Fig. 2, where the bycatch harvesting intensity of Métier $2\left(v_{12}\right)$ is depicted along the horizontal axis. All other parameters including the preference for fish consumption are set according to Table 1 . The progression of stock levels in response to increasing bycatch intensity further illustrates the previous result. Instead of the stock of Species 1 decreasing with increasing harvesting efficiency for that species, it is instead the stock of Species 2 that is more strongly affected. Stocks of Species 1 are even increasing for a large parameter range. This adjustment is caused by the economic actors optimizing given each of the parametrisations. Higher harvesting efficiency of Métier 2 makes it more profitable, increasing the corresponding number of firms (keeping profits zero), and correspondingly increasing harvests of both species. The increased harvests drive down prices. Thereby, simultaneously, Métier 1 becomes comparatively less profitable, reducing the number of firms practising it. This in 

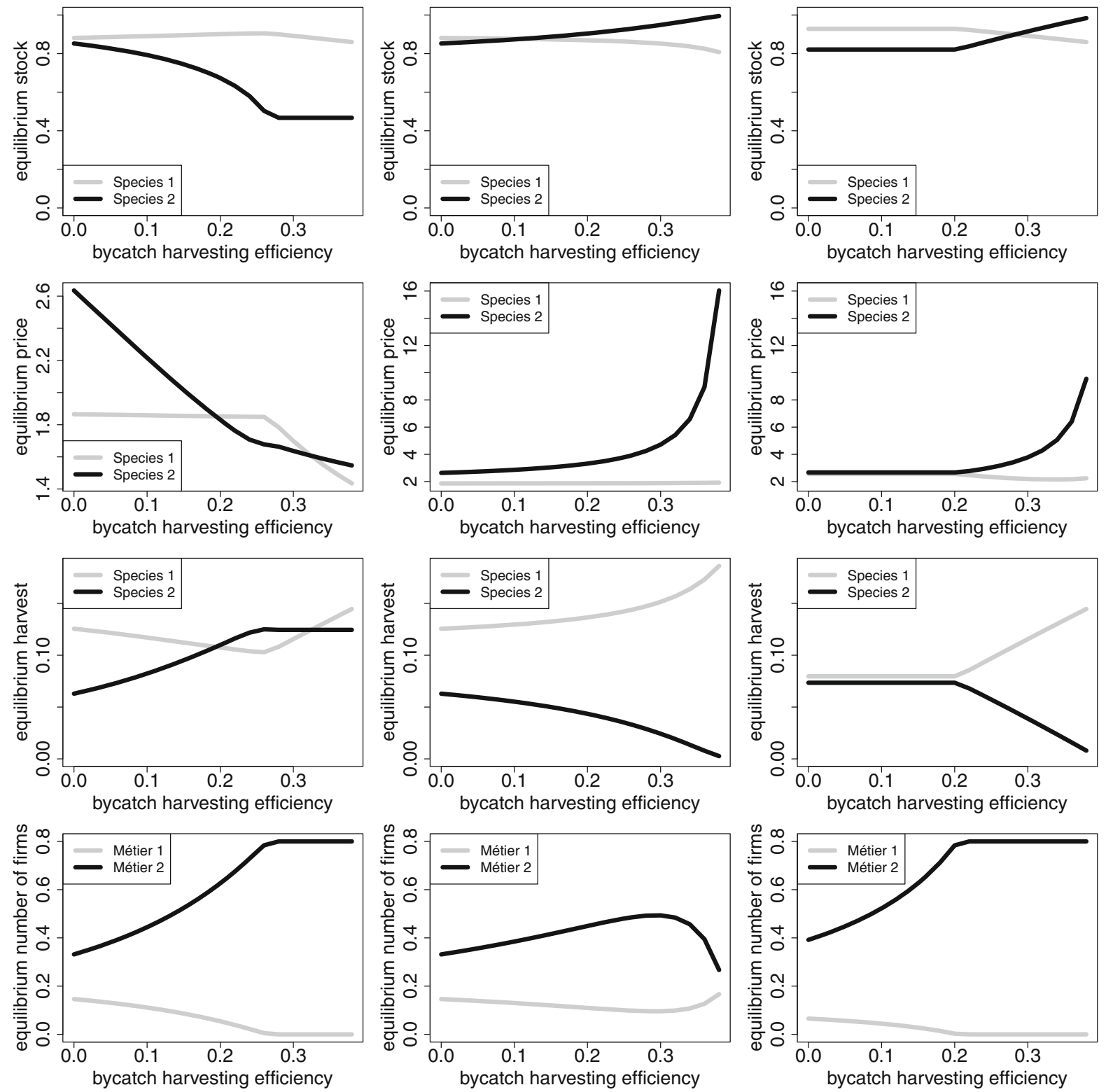

Fig. 2 Interior equilibrium values of the model for stocks, prices, harvests and number of firms, given fully endogenous economic variables. Bycatch harvesting efficiency of Métier 2 $\left(v_{12}\right)$ is depicted along the horizontal axis. For the left column, all other parameters are kept at their default values (Table 1).

For the centre and right columns, increases in the bycatch harvesting efficiency of Métier 2 are offset by decreases in the targeted harvesting efficiency of the same métier. Fixed costs of harvesting are adjusted to satisfy Eq. (36)

turn decreases harvesting pressure for Species 1 . The latter effect overcompensates the direct effect of the increased harvesting efficiency for that species, yielding larger stocks. This type of adjustment breaks down when Métier 1 is completely abandoned $\left(v_{12} \geq 0.28\right)$, which occurs when the condition for switching between cases (34) is met. In that domain, most indirect adjustment mechanisms are no longer active. Hence, the direct effect of changes in the harvesting efficiency for the single métier can be observed.

The above effect is primarily driven by the increase in profitability of the métier with bycatch. However, given that the capacity of a fishing vessel is fixed, the 
increase in harvesting efficiency of a métier for a specific species may be associated with a decrease in the targeted harvest, keeping the total harvesting efficiency of a given métier $\sum_{i} v_{i k}$ constant. The longterm steady states, when bycatch is introduced with this restriction on overall harvesting efficiency, are shown in the centre column of Fig. 2. These results are dominated by the direct effect of the changed harvesting efficiencies of Métier 2 (increasing for Species 1, decreasing for Species 2). The indirect effects, i.e. changes in the number of firms practising each of the métiers, are not strong enough in this case to overcome the direct effects. This shows that while the indirect effects can significantly alter outcomes, their strength depends on the specific manner in which bycatch changes harvesting properties. This can be seen as a limitation of the previous result.

An analytical result of the model is the condition on model parameters under which direct and indirect effects perfectly balance each other shown by Eq. (36). It specifies the relationship between métier fixed costs, harvesting efficiencies and returns to effort in harvesting that must hold for bycatch to not change longterm steady states. The right column of Fig. 2 shows the long run steady states of the model, with fix costs adjusted to satisfy condition (36). From these, a limitation of this condition is immediately apparent: as before, indirect effects are only present while both métiers are practised. For bycatch intensities where only Métier 2 is practised, only the direct effects of changes in the harvesting efficiencies are left.

\section{Discussion and conclusion}

In this paper, the impact of bycatch is investigated in the context of ecosystem stocks developing over multiple periods with fishers and consumers acting independently to achieve their respective goals. The addition of the further source of interaction between harvested amounts of different species causes significant changes in model dynamics and equilibria. These changes are partly due to the direct effect of the increased total harvesting efficiency for individual species and partly due to indirectly caused changes in harvesting effort by fishers. With the model presented in this paper, it is possible to investigate both direct and indirect effects simultaneously and determine their relative importance. The model presented is to my knowledge the first to include interactions between harvested species within the ecosystem, in harvesting and in consumer demand in a single analytically solvable model.

The main adjustment mechanism within the model, causing indirect effects on harvesting pressure, is through prices for individual species on the consumer market and fleet sizes. Based on straight forward relationships between ecosystem stocks, harvesting costs and prices, the latter adjust to changing stocks, varying over time and parametrisations. Consumer demand in turn takes into account not only the prices of individual species but also of substitutes. Fleet sizes then adjust in order for supply to meet demand. Independently of bycatch, this effect has the potential to cause significantly increased harvesting pressures on individual species, as the availability of others decline (Quaas \& Requate, 2013). With the inclusion of bycatch this effect is exasperated, as increased prices not only increase harvesting pressures for the individual species, but also for bycatch species.

In much of the literature concerning multi-species fisheries, these indirect effects are either omitted either by only considering single periods or by the assumption that prices do not respond to changes in harvests even if multiple periods are considered (e.g. Herrera, 2005; Singh \& Weninger, 2009; Holland, 2010). Where the focus is entirely on the short-term choices of fishers (e.g. Boyce, 1996; Abbott \& Wilen, 2009) this is a reasonable approach. The fisher choice problem within this paper is modelled in a similar way. But doing so, without a dynamic component in the model, precludes the analysis of longer term implications of the harvesting choices thereby derived. Conversely, the literature focused on the importance of consumer choice in multi-species fisheries have so far omitted bycatch (e.g. Baumgärtner et al., 2011; Quaas \& Requate, 2013). The main contribution of this paper to the literature then is in demonstrating the importance of these interrelated interactions between harvested species and identifying a special case where these effects cancel each other out. This cancellation of effects rests on the assumption of free entry and exit on the fisheries market. Any barriers to entry, such as long-term capital investments into vessels, would negate this result.

Hence, with regard to the development of management methods using economic models, aside from the 
special cases given by the conditions for no effect of bycatch, it appears to be necessary to take not only bycatch into account, but also the other sources of interaction between different species identified in this paper. If management measures are designed without these considered, the decision maker is implicitly under the impression that each species can be managed independently. However, due to these avenues of interaction between different species, a policy aimed at one will have cross-impacts on other species present in the ecosystem. The most likely result of this would be over-harvesting. For example, consider an abundant species being harvested by a métier that, unknown to the decision maker, also has a large bycatch of a more fragile species. In this case, the determined management measure on practising that métier would be too lax, leading to over-fishing of the bycatch species. To avoid such outcomes, this model can be used to determine optimal fisheries management while taking bycatch and its direct and indirect effects into account.

The answer to the question posed in the title, if bycatch should be considered in modelling the interactions of fisheries, fishers and consumers therefore is the classical economist's answer: "It depends". It depends on the strength of the bycatch inherent in the métiers to be modelled. It also depends on the variables of interest to the modeller. While the error made for stocks, harvests and prices by omitting bycatch may be small, or even zero in special cases, it may be large for the number of firms. It may even change qualitative results such as the survival of species and which métiers are practised. While changes in the number of active firms are not of immediate importance regarding ecosystem management, they imply changes in employment which tends to be important to decisions makers in general. This is especially the case where the number of firms is declining, implying decreased opportunity for employment in this sector. As the condition for bycatch to have no effect on stocks, harvests and prices is quite narrow a more general answer is "yes".

Acknowledgements I thank $H$. Held for verifying the equations derived in this paper and for helpful discussions. Furthermore, I thank M. D. Blanz for helpful comments and proofreading the manuscript.
Funding Funding by the German Federal Ministry of Education and Science as part of the NOAH Projects (Grant Numbers 03F0670A and 3F0742C) is gratefully acknowledged.

Open Access This article is distributed under the terms of the Creative Commons Attribution 4.0 International License (http:// creativecommons.org/licenses/by/4.0/), which permits unrestricted use, distribution, and reproduction in any medium, provided you give appropriate credit to the original author(s) and the source, provide a link to the Creative Commons license, and indicate if changes were made.

\section{References}

Abbott, J. K. \& J. E. Wilen, 2009. Regulation of fisheries bycatch with common-pool output quotas. Journal of Environmental Economics Management 57: 195-204.

Asche, F., F. Steen \& K. G. Salvanes, 1997. Market delineation and demand structure. American Journal of Agricultural Economics 79: 139-150.

Barten, A. P. \& L. J. Bettendorf, 1989. Price formation of fish: an application of an inverse demand system. European Economic Review 33: 1509-1525.

Baumgärtner, S., S. Derissen, M. F. Quaas \& S. Strunz, 2011. Consumer preferences determine resilience of ecologicaleconomic systems. Ecology \& Society 16(4): 9.

Borges, L., 2015. The evolution of a discard policy in europe. Fish and Fisheries 16: 534-540.

Boyce, J. R., 1996. An economic analysis of the fisheries bycatch problem. Journal of Environmental Economics and Management 31: 314-336.

Clark, C. W., 1990. Mathematical Bioeconomics. Wiley, New York.

Davies, R. W. D., S. J. Cripps, A. Nickson \& G. Porter, 2009. Defining and estimating global marine fisheries bycatch. Marine Policy 33: 661-672.

Davis, M. W., 2002. Key principles for understanding fish bycatch discard mortality. Canadian Journal of Fisheries and Aquatic Sciences 59: 1834-1843.

Derissen, S., M. F. Quaas \& S. Baumgärtner, 2011. The relationship between resilience and sustainability of ecological-economic systems. Ecological Economics 70: 1121-1128.

Dixit, A. K. \& J. E. Stiglitz, 1977. Monopolistic competition and optimum product diversity. The American Economic Review 67: 297-308.

Fousekis, P. \& B. J. Revell, 2004. Retail fish demand in great britain and its fisheries management implications. Marine Resource Economics 19: 495-510.

Hall, M. A., D. L. Alverson \& K. I. Metuzals, 2000. By-catch: problems and solutions. Marine Pollution Bulletin 41: 204-219.

Harrington, J. M., R. A. Myers \& A. A. Rosenberg, 2005. Wasted fishery resources: discarded by-catch in the usa. Fish and Fisheries 6: 350-361. 
Herrera, G. E., 2005. Stochastic bycatch, informational asymmetry, and discarding. Journal of Environmental Economics and management 49: 463-483.

Holland, D. S., 2010. Markets, pooling and insurance for managing bycatch in fisheries. Ecological Economics 70: 121-133.

Kuhn, H. W., 2014. Nonlinear programming: a historical view. Traces and Emergence of Nonlinear Programming. Birkhäuser, Basel: 393-414.

Lewison, R. L., L. B. Crowder, A. J. Read \& S. A. Freeman, 2004. Understanding impacts of fisheries bycatch on marine megafauna. Trends in Ecology \& Evolution 19: 598-604.

Möllmann, C., M. Lindegren, T. Blenckner, L. Bergström, M. Casini, R. Diekmann, J. Flinkman, B. Müller-Karulis, S. Neuenfeldt, J. O. Schmidt, et al., 2014. Implementing ecosystem-based fisheries management: from single-species to integrated ecosystem assessment and advice for baltic sea fish stocks. ICES Journal of Marine Science: Journal du Conseil 71: 1187-1197.

Nieminen, E., M. Lindroos \& O. Heikinheimo, 2012. Optimal bioeconomic multispecies fisheries management: a baltic sea case study. Marine Resource Economics 27: 115-136.
Quaas, M. F. \& T. Requate, 2013. Sushi or fish fingers? seafood diversity, collapsing fish stocks, and multispecies fishery management. The Scandinavian Journal of Economics 115: 381-422.

Quaas, M. F., D. Van Soest \& S. Baumgärtner, 2013. Complementarity, impatience, and the resilience of natural-resource-dependent economies. Journal of Environmental Economics and Management 66: 15-32.

R Core Team, 2017. R: A Language and Environment for Statistical Computing. R Foundation for Statistical Computing. Vienna. https://www.R-project.org/.

Singh, R. \& Q. Weninger, 2009. Bioeconomies of scope and the discard problem in multiple-species fisheries. Journal of Environmental Economics and Management 58: 72-92.

Skonhoft, A., N. Vestergaard \& M. F. Quaas, 2012. Optimal harvest in an age structured model with different fishing selectivity. Environmental and Resource Economics 51: 525-544.

Soetaert, K. \& P. M. J. Herman, 2009. A Practical Guide to Ecological Modelling. Using R as a Simulation Platform. Springer, Dordrecht. 